Vegetalika. 2018. 7(2): 1-15

\title{
Evaluasi Tipe Pemanfaatan Lahan Pertanian dalam Upaya Mitigasi Kerusakan Lahan Di Desa Giritirta, Kecamatan Pejawaran, Kabupaten Banjarnegara
}

\section{Evaluation of the Agricultural Land Utilization Types for Mitigation of Land Degradation in Giritirta, Pejawaran, Banjarnegara}

\author{
Bayu Setiawan ${ }^{1)}$, Prapto Yudono ${ }^{2)}$, Sriyanto Waluyo ${ }^{2)^{*}}$ ) \\ 1) Program Studi Agronomi, Fakultas Pertanian, Universitas Gadjah Mada \\ 2) Departemen Budidaya Pertanian, Fakultas Pertanian, Universitas gadjah Mada \\ *) Penulis untuk koresponden Email: sriyanto.waluyo@ugm.ac.id
}

\begin{abstract}
Vegetables and flowers are produced under andisol and alfisol soils with elevations ranging from 350-1500 $\mathrm{m}$ above sea level (asl). Potatoe in Indonesia is a plant that has promosing economic value, so farmers are competing to plant the crop. Mountainous lands that were utilized into agricultural land needs to evaluate based on type of land use in order to know the potential of production and the impact of land damage that arises. This research had been conducted in Giritirta, Pejawaran, Banjarnegara, Central Java implemented on July 2017-November 2017. The method used was survei research on land quality with direct field observation, and collecting data from relevant agencies, and survei on farmer response was conducted by interview. Primary data taken was data obtained directly from the object of research through observation, interview with questionnaire, secondary data compiled were data obtained by previous researchers. The results showed that usage for agricultural in the location of the research in the form of cultivation annual crops the usable land with potatoe (Solanum tuberosum L.) as main crop and the technique of planting by aranging the slope with minimum land conservation measures. The level of erosion hazard is classified in very heavy class on all of Land Unit which causes the potential for high land degradation in a short time. The way mitigation to avoiding the damage by implementation on planting coffee arabica and tea in steep land (26\%-40\%) and quinine in very steep land (>40\%). Land improvements made by making and repairing terraces land, strip grass and making rorak.
\end{abstract}

Key words: sloping land, erosion, evaluation, potatoes, mitigation, conservation

\section{INTISAR I}

Tanaman sayur-sayuran dan bunga-bungaan banyak dihasilkan di tanah andisol dan alfisol dengan elevasi berkisar antara 350-1500 m di atas permukaan laut (dpl). Kentang di Indonesia merupakan tanaman yang memiliki nilai ekonomis cukup menjanjikan, sehingga petani berlomba-lomba untuk menanam tanaman tersebut. Lahan pegunungan yang sudah dimanfaatkan menjadi lahan pertanian perlu dilakukan evaluasi tipe pemanfaatan lahan guna mengetahui potensi produksi dan dampak kerusakan lahan yang timbul. Penelitian ini dilakukan di desa Giritirta, kecamatan Pejawaran, kabupaten Banjarnegara, Jawa Tengah yang dilaksanakan pada bulan Juli 2017-November 2017. Metode yang digunakan adalah penelitian survei terhadap kualitas lahan dengan pengamatan langsung di lapangan, dan mengumpulkan data- 
data dari instansi terkait, serta survei terhadap respons petani yang dilakukan dengan wawancara. Data primer yang diambil adalah data yang diperoleh secara langsung dari objek penelitian melalui kegiatan observasi, wawancara dan/atau kuisioner. Data sekunder adalah data yang diperoleh peneliti dari sumber yang sudah ada. Pemanfaatan lahan pertanian di lokasi penelitian berupa budidaya tanaman semusim dengan komoditas utama kentang (Solanum tuberosum L.) dengan teknik penanaman searah lereng serta minim tindakan konservasi lahan. Tingkat bahaya erosi tergolong dalam klas sangat berat di semua satuan lahan yang menyebabkan potensi kerusakan lahan tinggi dalam kurun waktu yang singkat. Cara mitigasi kerusakan lahan yang cocok untuk dilaksanakan yaitu dengan penanaman kopi arabika dan teh pada kelerengan curam (26\%-40\%) serta tanaman kina pada kelerengan sangat curam (>40\%). Perbaikan lahan yang dilakukan dengan pembuatan dan perbaikan teras, penanaman strip rumput, serta pembuatan rorak

Kata Kunci : lahan miring, erosi, evaluasi, kentang, mitigasi, konservasi

\section{PENDAHULUAN}

Indonesia merupakan negara yang daratannya terdiri dari $45 \%$ gunung dan pegunungan. Lahan pegunungan merupakan lahan yang memiliki elevasi $\geq 350 \mathrm{~m} \mathrm{dpl}$ dan/atau dengan tingkat kemiringan lereng $\geq 15 \%$ (Permentan, 2006). Tanaman sayursayuran dan bunga-bungaan dihasilkan di tanah Andisol dan Alfisol dengan elevasi berkisar antara 350-1500 m di atas permukaan laut (dpl). Tanaman pekebunan seperti kopi, teh, kina, dan berbagai jenis buah-buahan juga banyak ditanam di lahan pegunungan. Walaupun berpeluang untuk budidaya pertanian, lahan pegunungan rentan terhadap longsor dan erosi karena tingkat kemiringannya, curah hujan relatif lebih tinggi, dan kondisi tanah yang tidak stabil.

Kentang di Indonesia merupakan tanaman yang memiliki nilai ekonomis cukup menjanjikan, sehingga petani berlomba-lomba untuk menanam tanaman tersebut. Pada awal penanaman kentang, hasil yang diperoleh tinggi karena lahan masih dalam kondisi baik. Pemanfaatan lahan yang terus-menerus serta penambahan bahan kimia dalam jumlah besar mengakibatkan kesuburan tanah semakin menurun dan lingkungan menjadi rusak.

Lahan pegunungan yang sudah dimanfaatkan menjadi lahan pertanian perlu dilakukan evaluasi tipe pemanfaatan lahan guna mengetahui potensi produksi dan dampak kerusakan lahan yang timbul. Evaluasi tipe pemanfaatan lahan menjadi hal yang perlu dilaksanakan dalam kegiatan konservasi tanah dan air di lahan pegunungan. Hasil dari evaluasi tersebut akan menghasilkan langkah konservasi yang diperlukan serta tindakan pengelolaan lahan agar dapat dipergunakan secara berkelanjutan sesuai dengan hambatan dan ancaman yang dikandungnya (Arsyad, 1989). 
Bayu Setiawan et al., / Vegetalika. 2018. 7(2): 1-15

\section{BAHAN DAN METODE PENELITIAN}

Bahan yang digunakan pada penelitian ini adalah peta jenis tanah, peta kemiringan lahan, peta penggunaan lahan dan peta satuan lahan (land unit). Sedangkan alat yang digunakan yaitu alat pengukur panjang, $\mathrm{pH}$ meter, kuisioner, dan alat tulis.

Penelitian ini merupakan penelitian survey terhadap kualitas lahan dengan pengamatan langsung di lapangan, dan mengumpulkan data-data dari instansi terkait, serta survey terhadap respons petani yang dilakukan dengan wawancara. Data dianalisis menggunakan analisis mempautkan (matching), yaitu dengan membandingkan kebutuhan tanaman (crop requirement) beberapa tanaman tahunan berdasarkan pustaka dengan kualitas lahan (land quality) yang ada di daerah penelitian menggunakan tabel matching. Diperoleh kelas kesesuaian lahan untuk beberapa tanaman tersebut pada masing-masing satuan lahan (land unit). Selanjutnya dilakukan pemilihan tanaman yang tepat serta pengelolaan lahan yang cocok sesuai dengan hasil evaluasi lahan.

\section{HASIL DAN PEMBAHASAN}

Lokasi penelitian merupakan lahan pegunungan yang memiliki lahan pertanian lebih luas dibandingkan dengan kawasan hutan dan pemukiman. Kondisi fisik tanah rentan terhadap bahaya erosi dan longsor. Komoditas hortikultura di lokasi penelitian dibudidayakan secara monokultur dan tumpangsari dengan pengolahan lahan yang intensif setiap tahunnya. Tanaman budidaya tidak menghendaki adanya persaingan dengan tumbuhan pengganggu yang dapat mengurangi serapan unsur hara di dalam tanah. Akibatnya tanaman penutup tanah lain yang sering dianggap gulma dibersihkan sehingga tanah dibiarkan terbuka tanpa adanya penutup lahan. Usaha tani yang dilakukan secara terus menerus dengan mengangkut hasil panenan keluar tanpa dilakukan upaya pengembalian kembali sisa bahan tersebut dan bahan organik lainnya akan menguras kesuburan tanah.

Lahan dengan kelerengan tinggi tidak dapat digunakan sebagai lahan pertanian berdasarkan tinggkat keamanan penggunaan. Banyak mekanisme yang harus dilaksanakan dalam pengolahan lahan dan membutuhkan modal yang cukup besar terkait pertanian dengan memperhatikan konservasi. Pemilihan tanaman juga harus dibatasi pada tanaman tertentu dan jumlahnya tidak banyak. Hal tersebut merupakan faktor utama yang sering diabaikan oleh petani dalam kegiatan usaha tani di lahan pegunungan. 
Bayu Setiawan et al., / Vegetalika. 2018. 7(2): 1-15

Lokasi penelitian berada pada ketinggian antara 1.100-1400 m dpl. Relief dan kelas lereng di lokasi penelitian disajikan pada Gambar 1.

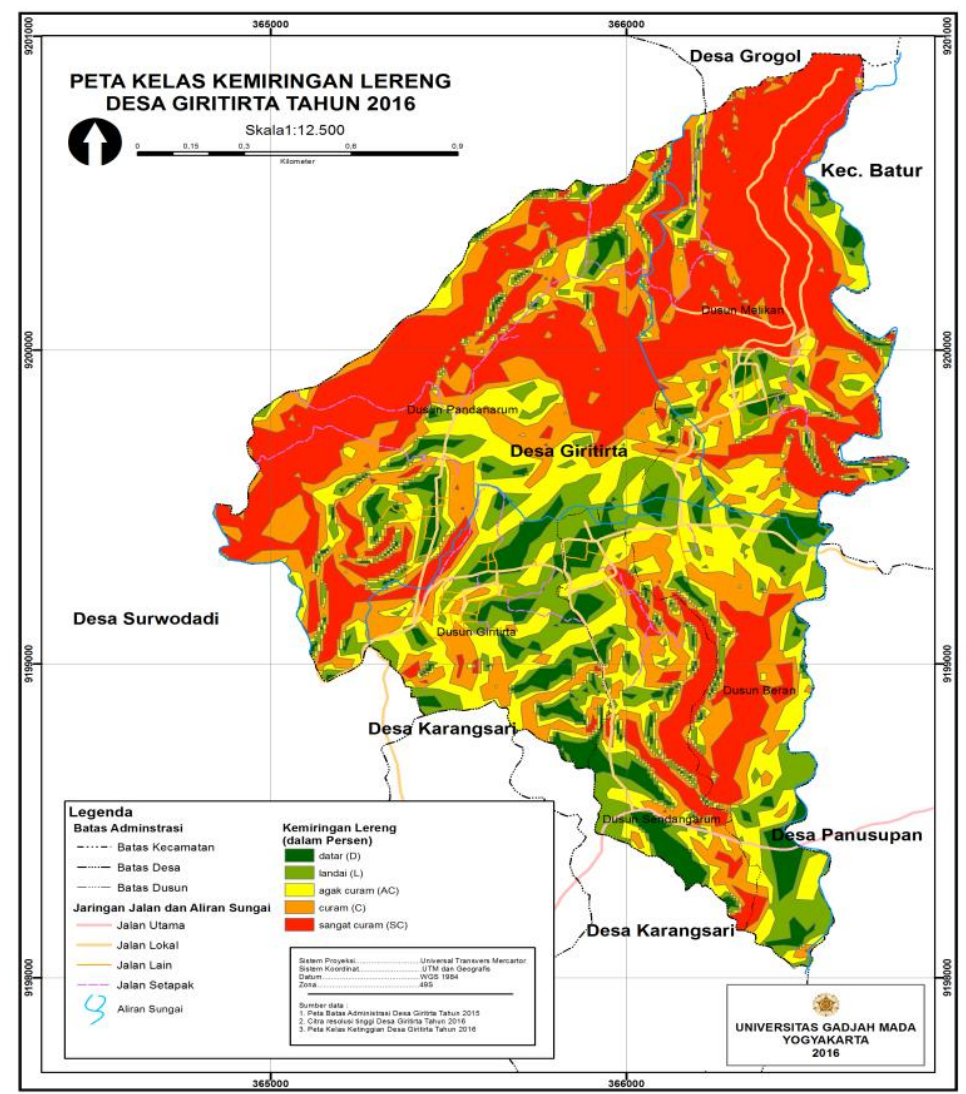

Gambar 1. Peta Kemiringan Lereng

Departemen Kehutanan menetapkan bahwa lahan dengan ketinggian $>2.000 \mathrm{~m}$ dpl dan/atau lereng $>40 \%$ merupakan kawasan hutan lindung, sehingga di lokasi penelitian terdapat $1.045 .748 \mathrm{~m}^{2}(36,03 \%)$ lahan yang seharusnya dijadikan sebagai kawasan hutan lindung guna pencegahan bahaya bencana.

Tabel 1. Curah hujan bulanan Kecamatan Pejawaran Tahun 2005-2014.

\begin{tabular}{|c|c|}
\hline Bulan & Rerata Curah Hujan Selama 10 Tahun \\
\hline Januari & 396,6 \\
\hline Februari & 403,8 \\
\hline Maret & 406,5 \\
\hline April & 284,7 \\
\hline Mei & 161,2 \\
\hline Juni & 89,9 \\
\hline Juli & 90,0 \\
\hline Agustus & 42,0 \\
\hline September & 62,3 \\
\hline Oktober & 204,5 \\
\hline November & 411,5 \\
\hline Desember & 524,3 \\
\hline Jumlah & 3077,3 \\
\hline
\end{tabular}

Sumber: Kantor Kecamatan Pejawaran Kabupaten Banjarnegara. 
Bayu Setiawan et al., / Vegetalika. 2018. 7(2): 1-15

Berdasarkan klasifikasi iklim yang dilakukan oleh Schmidt-Ferguson (1951), lokasi penelitian tergolong ke dalam iklim Tipe A yaitu daerah sangat basah dengan ciri vegetasi hutan hujan tropika. Hujan terjadi hampir sepanjang tahun di lokasi penelitian dengan intensitas yang cukup tinggi.

Prediksi erosi merupakan cara yang digunakan untuk memperkirakan laju erosi yang akan terjadi dari tanah yang dipergunakan dengan penggunaan lahan dan tindakan pengelolaan lahan tertentu. Prediksi erosi dapat digunakan untuk memperkirakan kebijakan penggunaan lahan serta tindakan konservasi tanah yang diperlukan. Model prediksi erosi yang umum digunakan di Indonesia adalah USLE (Universal Soil Lost Equation). USLE adalah model prediksi erosi yang dirancang untuk memprediksi erosi jangka panjang. Metode USLE dikembangkan oleh Wischmeier dan Smith (1978), dengan rumus:

\section{$A=R \times K \times L S \times C \times P$}

Keterangan :
$A=$ jumlah kehilangan tanah akibat erosi (ton/ha/tahun),
$\mathrm{R}=$ indeks erosivitas hujan,
$\mathrm{K}=$ faktor erodibilitas tanah,
$\mathrm{LS}=$ faktor panjang dan kemiringan lahan,
$\mathrm{C}=$ faktor penutupan vegetasi dan pengelolaan tanaman, dan
$P=$ faktor pengelolaan lahan/tindakan konservasi tanah.

Selanjutnya Departemen Kehutanan (2006), membagi tingkat bahaya erosi menjadi beberapa kelas berdasarkan besarnya erosi dan solum tanah.

Tabel 2. Kelas tingkat bahaya erosi

\begin{tabular}{|c|c|c|c|c|c|}
\hline \multirow{4}{*}{$\begin{array}{l}\text { Solum Tanah } \\
\text { (cm) }\end{array}$} & \multicolumn{5}{|c|}{ Kelas Erosi } \\
\hline & $\mathrm{I}$ & II & III & IV & $\mathrm{V}$ \\
\hline & \multicolumn{5}{|c|}{ Erosi ( Ton/ha/tahun) } \\
\hline & $<15$ & $15-60$ & $60-180$ & $180-480$ & $>480$ \\
\hline $\begin{array}{l}\text { Dalam } \\
(>90)\end{array}$ & $\begin{array}{l}\text { Sangat } \\
\text { Ringan }\end{array}$ & Ringan & Sedang & Berat & $\begin{array}{c}\text { Sangat } \\
\text { Berat }\end{array}$ \\
\hline $\begin{array}{l}\text { Sedang } \\
(60-90)\end{array}$ & Ringan & Sedang & Berat & $\begin{array}{c}\text { Sangat } \\
\text { Berat }\end{array}$ & $\begin{array}{c}\text { Sangat } \\
\text { Berat }\end{array}$ \\
\hline $\begin{array}{l}\text { Dangkal } \\
(30-60)\end{array}$ & Sedang & Berat & $\begin{array}{c}\text { Sangat } \\
\text { Berat }\end{array}$ & $\begin{array}{c}\text { Sangat } \\
\text { Berat }\end{array}$ & $\begin{array}{c}\text { Sangat } \\
\text { Berat }\end{array}$ \\
\hline $\begin{array}{c}\text { Sangat Dangkal } \\
(<30)\end{array}$ & Berat & $\begin{array}{c}\text { Sangat } \\
\text { Berat }\end{array}$ & $\begin{array}{c}\text { Sangat } \\
\text { Berat }\end{array}$ & $\begin{array}{c}\text { Sangat } \\
\text { Berat }\end{array}$ & $\begin{array}{c}\text { Sangat } \\
\text { Berat }\end{array}$ \\
\hline
\end{tabular}

Sumber: Departemen Kehutanan (1998)

Setelah semua faktor diketahui nilainya, selanjutnya di masukkan ke dalam persamaan USLE dan diperoleh hasilnya sebagai berikut: 
Bayu Setiawan et al., / Vegetalika. 2018. 7(2): 1-15

Tabel 3. Prediksi erosi di lokasi penelitian

\begin{tabular}{|c|c|c|c|c|c|}
\hline $\begin{array}{l}\text { Kemiringan } \\
\text { (Solum } \\
\text { Tanah) }\end{array}$ & $\begin{array}{l}\text { Panjang } \\
\text { Lereng }\end{array}$ & $\begin{array}{l}\text { Tindakan } \\
\text { Konservasi } \\
\text { Tanah }\end{array}$ & $\begin{array}{c}\text { Penutupan vegetasi } \\
\text { dan Pengelolaan } \\
\text { tanaman }\end{array}$ & $\begin{array}{l}\text { Prediksi Erosi } \\
\text { (Ton/ha/thn) }\end{array}$ & $\begin{array}{c}\text { Kelas } \\
\text { Bahaya } \\
\text { Erosi }\end{array}$ \\
\hline \multirow[t]{4}{*}{$\begin{array}{l}16 \%-25 \% \\
(65 \mathrm{~cm})\end{array}$} & $68 \mathrm{~m}$ & $\begin{array}{l}\text { Teras bangku, } \\
\text { jelek }\end{array}$ & Cabai, Tomat, & 754,73 & $\begin{array}{c}\text { Sangat } \\
\text { Berat }\end{array}$ \\
\hline & $99 \mathrm{~m}$ & $\begin{array}{l}\text { Bedengan untuk } \\
\text { sayuran }\end{array}$ & $\begin{array}{l}\text { Lobis, cabai, } \\
\text { loncang, tomat, } \\
\text { sawi, sledri, semak, } \\
\text { ubi, tembakau }\end{array}$ & 317,10 & $\begin{array}{c}\text { Sangat } \\
\text { Berat }\end{array}$ \\
\hline & $74 \mathrm{~m}$ & Kontur cropping & Cabai, talas, jagung & $1.147,25$ & $\begin{array}{c}\text { Sangat } \\
\text { Berat }\end{array}$ \\
\hline & $76 \mathrm{~m}$ & $\begin{array}{l}\text { Teras bangku, } \\
\text { jelek }\end{array}$ & $\begin{array}{l}\text { Semak, lahan tidak } \\
\text { diolah }\end{array}$ & $1.082,86$ & $\begin{array}{c}\text { Sangat } \\
\text { Berat }\end{array}$ \\
\hline \multirow[t]{4}{*}{$\begin{array}{c}26 \%-40 \% \\
(60 \mathrm{~cm})\end{array}$} & $25 \mathrm{~m}$ & $\begin{array}{l}\text { Bedengan untuk } \\
\text { sayuran }\end{array}$ & Kentang, cabai & 381,67 & $\begin{array}{c}\text { Sangat } \\
\text { Berat }\end{array}$ \\
\hline & $35 \mathrm{~m}$ & $\begin{array}{l}\text { Bedengan untuk } \\
\text { sayuran }\end{array}$ & $\begin{array}{l}\text { Kentang, semak, } \\
\text { jagung } \\
\text { Buncis, cabai, }\end{array}$ & 462,89 & $\begin{array}{c}\text { Sangat } \\
\text { Berat }\end{array}$ \\
\hline & $113 \mathrm{~m}$ & $\begin{array}{l}\text { Bedengan untuk } \\
\text { sayuran }\end{array}$ & $\begin{array}{l}\text { rumput gajah, } \\
\text { jagung, lobis, sledri, } \\
\text { semak }\end{array}$ & 710,02 & $\begin{array}{c}\text { Sangat } \\
\text { Berat }\end{array}$ \\
\hline & $87 \mathrm{~m}$ & $\begin{array}{l}\text { Teras bangku, } \\
\text { jelek }\end{array}$ & $\begin{array}{l}\text { Jagung, kapri, } \\
\text { semak }\end{array}$ & 605,20 & $\begin{array}{c}\text { Sangat } \\
\text { Berat }\end{array}$ \\
\hline \multirow[t]{6}{*}{$\begin{array}{l}>40 \% \\
(50 \mathrm{~cm})\end{array}$} & $100 \mathrm{~m}$ & $\begin{array}{l}\text { Bedengan untuk } \\
\text { sayuran }\end{array}$ & $\begin{array}{l}\text { Buncis, lobis, } \\
\text { jagung. }\end{array}$ & $1.260,01$ & $\begin{array}{c}\text { Sangat } \\
\text { Berat }\end{array}$ \\
\hline & $38 \mathrm{~m}$ & $\begin{array}{l}\text { Bedengan untuk } \\
\text { sayuran }\end{array}$ & Tembakau, semak & 571,12 & $\begin{array}{c}\text { Sangat } \\
\text { Berat }\end{array}$ \\
\hline & $65 \mathrm{~m}$ & $\begin{array}{l}\text { Bedengan untuk } \\
\text { sayuran }\end{array}$ & Kentang, cabai & $1.239,94$ & $\begin{array}{c}\text { Sangat } \\
\text { Berat }\end{array}$ \\
\hline & $160 \mathrm{~m}$ & $\begin{array}{l}\text { Bedengan untuk } \\
\text { sayuran }\end{array}$ & $\begin{array}{l}\text { Cabai, daun } \\
\text { bawang, jagung, } \\
\text { lobis, wortel, tomat, } \\
\text { waluh, pisang, } \\
\text { semak }\end{array}$ & $1.570,37$ & $\begin{array}{c}\text { Sangat } \\
\text { Berat }\end{array}$ \\
\hline & $79 \mathrm{~m}$ & $\begin{array}{l}\text { Bedengan untuk } \\
\text { sayuran }\end{array}$ & Kentang & $1.482,25$ & $\begin{array}{c}\text { Sangat } \\
\text { Berat }\end{array}$ \\
\hline & $130 \mathrm{~m}$ & $\begin{array}{l}\text { Bedengan untuk } \\
\text { sayuran }\end{array}$ & $\begin{array}{l}\text { Nanas, buncis, } \\
\text { semak, lobis, } \\
\text { kentang, cabai }\end{array}$ & $1.331,00$ & $\begin{array}{c}\text { Sangat } \\
\text { Berat }\end{array}$ \\
\hline
\end{tabular}

Sumber: Pengamatan dan perhitungan di lapangan

Menurut Departemen Kehutanan, tingkat bahaya erosi di lokasi penelitian tergolong sangat berat. Panjang lereng sangat mempengaruhi tingkat bahaya erosi suatu tempat. Semakin panjang lereng yang dimanfaatkan lahannya tanpa saluran air sebagai tempat berkumpulnya aliran air maka aliran permukaan di saat hujan semakin dengan membawa materi berupa lapisan atas tanah yang semakin banyak.

Penggunaan lahan (landuse) diartikan sebagai bentuk intervensi atau campur tangan manusia terhadap lahan dalam rangka memenuhi kebutuhan hidupnya baik materiil maupun spirituil (Arsyad, 1989). Penggunaan lahan secara umum berdasarkan Pedoman Penyusunan Pola Rehabilitasi Lahan dan Konservasi Tanah dapat 
Bayu Setiawan et al., / Vegetalika. 2018. 7(2): 1-15

diklasifikasikan menjadi sawah dan tambak, hutan dan perkebunan, tegal diteras, semak belukar, kebun campuran, alang-alang, permukiman, padang rumput, pertanian lahan kering tanpa teras, lahan terbuka, tubuh air (Sutikno, 1996 cit Sumartono, 2011).

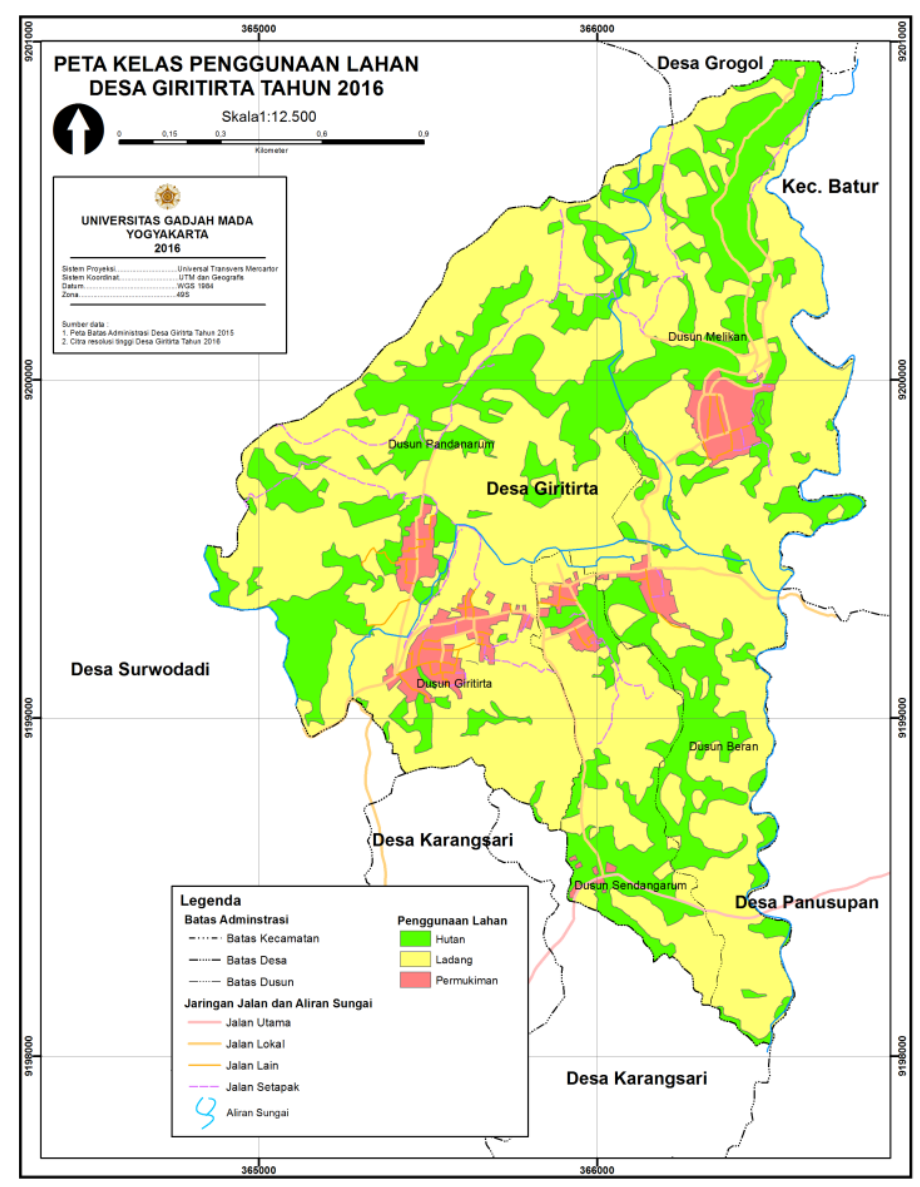

Gambar 2. Peta penggunaan lahan

Potensi ekonomi sektor pertanian pada lahan pegunungan cukup tinggi terutama bagi beberapa komoditas hortikultura. Lokasi penelitian yang termasuk daerah pegunungan dengan relief bergelombang sejatinya merupakan daerah konservasi air dengan pemanfaatan lahan yang dianjurkan berupa hutan tanaman tahunan atau percampuran tanaman tahunan dan semusim.

Budidaya pertanian di daerah pegunungan meliputi dua kegiatan pokok, yaitu kegiatan usahatani dan konservasi. Kegiatan usahatani pada hakekatnya adalah pemanfaatan sumberdaya lahan, yang dimiliki oleh petani (dikelola secara individual, berkelompok atau pengusaha) melalui penanaman tanaman dan/atau pemeliharaan ternak dengan memperhatikan keterkaitan antar komoditas secara harmonis agar hasil yang diperoleh optimal. 
Bayu Setiawan et al., / Vegetalika. 2018. 7(2): 1-15

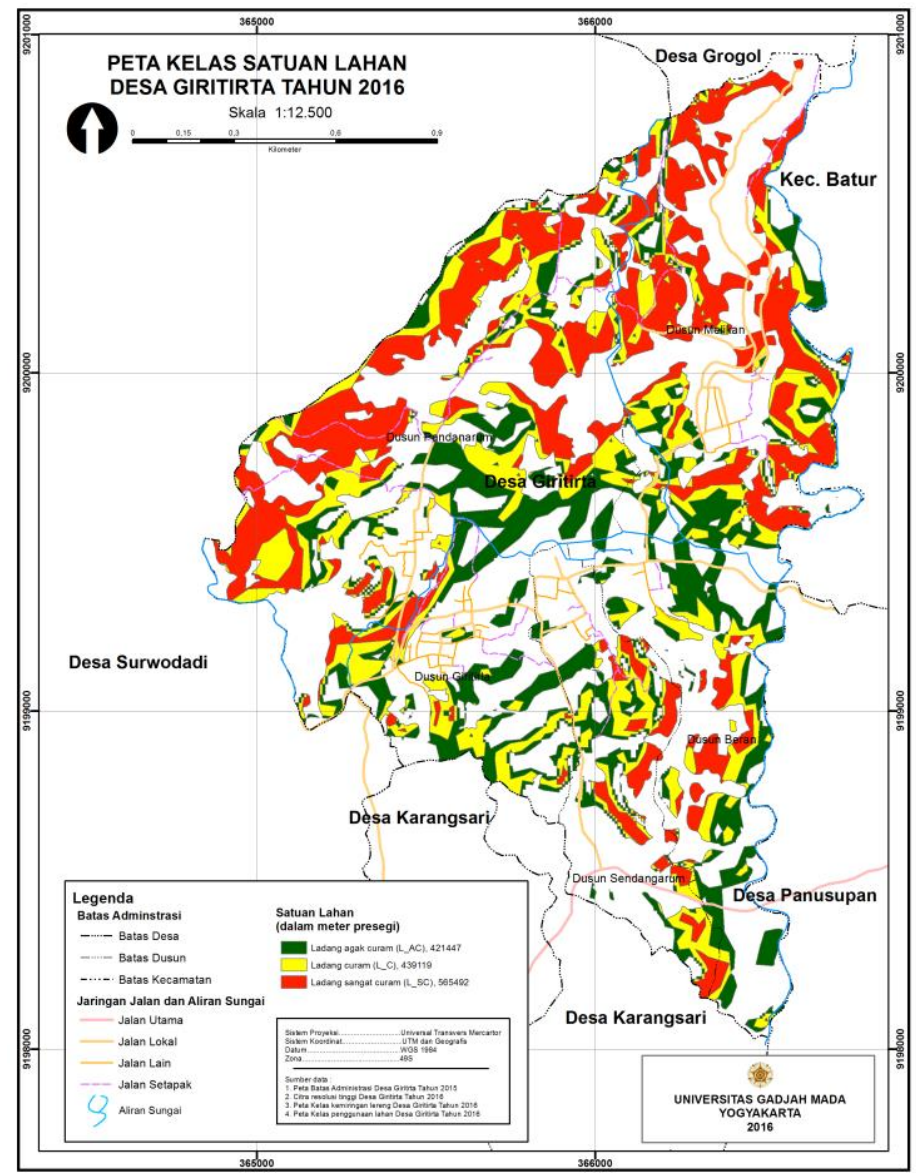

Gambar 3. Peta daerah kajian penelitian

Luas daerah yang merupakan penyalahgunaan lahan di lokasi sebesar $49,13 \%$ atau setengah dari luas wilayah desa Giritirta. Hasil tersebut mengacu terhadap Peraturan Menteri Pertanian No 47 Tahun 2006 yaitu pada lahan berlereng $>15 \%$ lebih diutamakan campuran tanaman semusim dengan tanaman tahunan atau sistem wanatani (agroforestri). Besarnya tingkat penyalahgunaan lahan menyebabkan perlu dilakukan penelitian lebih lanjut terkait pemanfaatan lahan pertanian pada kawasan lindung serta alternatif penggunaan lahan yang cocok sebagai upaya mitigasi kerusakan lahan.

Antusiasme petani dalam budidaya kentang sangat tinggi, seperti melakukan pengelolaan lahan dan tanaman intensif, penggunaan jenis tanaman sama berturutturut, serta menggunakan masukan luar tinggi. Dua dasa warsa berlangsung, gejala penurunan produktifitas kentang mulai tampak. Gejala tersebut berupa lapisan tanah olah menipis dan bahkan hilang akibat erosi; akibatnya tanah tidak mampu menopang pertumbuhan dan hasil tanaman kentang dengan baik tanpa masukan energi lebih tinggi. Munculnya organisme pengganggu tanaman (OPT) baru menambah semakin kompleks dan semakin sulit pengendaliannya. Penggunaan 
Bayu Setiawan et al., / Vegetalika. 2018. 7(2): 1-15

pestisida, fungisida dan herbisida terus menerus dapat berakibat menambah immunitas OPT serta menambah beban pekerjaan dan biaya produksi disamping itu juga mengakibatkan pencemaran bahan kimia pertanian didalam tanah (Waluyo, 2105).

Evaluasi kesesuaian lahan merupakan penggambaran tingkat kecocokan sebidang lahan untuk suatu penggunaan tertentu. Kelas kesesuaian suatu areal dapat berbeda tergantung daripada tipe penggunaan lahan yang sedang dipertimbangkan. Penilaian kesesuaian lahan pada dasarnya dapat berupa pemilihan lahan yang sesuai untuk tanaman tertentu. Hasil evaluasi lahan akan memberikan informasi arahan penggunaan lahan sesuai dengan keperluan tertentu.

Karakteristik lahan adalah sifat lahan yang dapat diukur atau diestimasi. Contohnya lereng, curah hujan, tekstur tanah, kapasitas air tersedia, kedalaman efektif dan sebagainya. Setiap satuan peta lahan yang dihasilkan dari kegiatan survei dan/atau pemetaan sumberdaya lahan, karakteristik lahan dirinci dan diuraikan yang mencakup keadaan fisik lingkungan dan tanah. Data tersebut digunakan untuk keperluan interpretasi dan evaluasi lahan bagi komoditas tertentu (Djaenudin et al., 2000 cit Hidayat 2006).

Tabel 4. Karakteristik lahan di lokasi penelitian

\begin{tabular}{lccc}
\hline \multicolumn{1}{c}{ Karakteristik lahan } & LU 1 & LU 2 & LU 3 \\
\hline Temperatur Rerata $\left({ }^{\circ} \mathrm{C}\right)$ & 20 & 20 & 18 \\
Curah Hujan (mm/Tahun) & 3077,3 & 3077,3 & 3077,3 \\
Drainase & Baik & Agak Baik & Agak Baik \\
Tekstur & Agak halus & Agak halus & Agak halus \\
Bahan Kasar & Sedikit & Sedikit & Sedikit \\
Kedalaman Tanah $(\mathrm{cm})$ & 65 & 60 & 50 \\
pH H2O & 5,8 & 5,8 & 5,8 \\
Lereng $(\%)$ & $16 \%-25 \%$ & $26 \%-40 \%$ & $>40 \%$ \\
Bahaya Erosi & Sangat Berat & Sangat Berat & Sangat Berat \\
\hline
\end{tabular}

Setelah diperoleh data karakteristik lahan di lokasi penelitian yang diperoleh dari analisis lapangan secara langsung dan informasi dari instansi terkait, selanjutnya dilakukan analisis mempautkan (matching) antara karakterisk lahan dengan syarat tumbuh komoditas tanaman untuk memperoleh tingkat kesesuaian lahan beberapa komoditas yang dibudidayakan. Komoditas yang di analisis tingkat kesesuaian lahannya yaitu kentang, lobis, cabai, tomat, selesdri, caisim, wortel, jagung dan tembakau. Komoditas tersebut merupakan komoditas yang dominan di budidayakan di lokasi penelitian. 
Bayu Setiawan et al., / Vegetalika. 2018. 7(2): 1-15

Tabel 5. Tingkat kesesuaian lahan beberapa komoditas di lokasi penelitian

\begin{tabular}{lccc} 
& \multirow{2}{*}{ Jenis Tanaman } & \multicolumn{3}{c}{ Nilai Kesesuaian Lahan } \\
\cline { 2 - 4 } & LU 1 & LU 2 & LU 3 \\
\hline Kentang & $\mathrm{Nwe}$ & Nwse & Nwse \\
Lobis & $\mathrm{Ne}$ & $\mathrm{Nse}$ & Nse \\
Cabai & $\mathrm{Ne}$ & $\mathrm{Nse}$ & Nse \\
Tomat & $\mathrm{Ne}$ & $\mathrm{Nse}$ & Nse \\
Seledri & $\mathrm{Ne}$ & $\mathrm{Nse}$ & Nse \\
Caisim & $\mathrm{Ne}$ & $\mathrm{Nse}$ & Nse \\
Wortel & $\mathrm{Nwe}$ & Nwse & Nwse \\
Jagung & $\mathrm{Ne}$ & Nse & Nse \\
Tembakau & $\mathrm{Ne}$ & Nse & Nse \\
\hline
\end{tabular}

Keterangan: $w=$ Rerata curah hujan, $s=$ Lereng, dan $e=$ Bahaya erosi

Berdasarkan tabel tingkat kesesuaian lahan diketahui bahwa semua komoditas pada semua land unit memiliki nilai kesesuaian lahan N. Parameter yang menjadi faktor pembatas utama yaitu lereng (s) dan bahaya erosi (e). Kemiringan lereng serta bahaya erosi menjadi faktor yang cukup dominan karena lokasi peneletian memiliki relief yang bergelombang dengan potensi bahaya erosi yang tinggi. Faktor pembatas inilah yang kemudian berdampak terhadap menurunnya produktivitas komoditas yang dibudidayakan berdasarkan hasil wawancara terhadap petani.

Faktor pembatas tambahan pada komoditas kentang dan wortel yaitu rerata curah hujan $(w)$. Curah hujan yang tinggi menyebabkan kandungan air di dalam tanah menjadi tinggi. Kentang dan wortel tergolong tanaman umbi-umbian (root crop) yang memiliki organ penyimpanan makanan/hasil di dalam tanah. Kondisi ini membuat kentang dan wortel tidak dapat menghasilkan pada kondisi tanah yang jenuh air seperti di lokasi penelitian.

Tanaman alternatif digunakan sebagai langkah awal tindakan konservasi lahan secara vegetatif. Pemilihan tanaman didasarkan terhadap tingkat hasil dan kemmpuannya dalam mengendalikan erosi lahan. Tanaman kopi arabika dan teh dipilih karena disamping memiliki nilai ekonomis, tajuk dan perakarannya memiliki kekuatan dalam melindungi tanah dari bahaya erosi. Tanaman kina dipilih karena merupakan tanaman tahunan yang dapat dijadikan komoditas hutan pada kelerengan yang sangat terjal guna mengurangi bahaya erosi dan longsor lahan. 
Bayu Setiawan et al., / Vegetalika. 2018. 7(2): 1-15

Tabel 6. Tingkat kesesuaian lahan kopi arabika, teh dan kina

\begin{tabular}{lccccccc}
\hline \multirow{2}{*}{ Karakteristik lahan } & \multicolumn{3}{c}{ Kopi Arabika } & \multicolumn{1}{c}{ Teh } & Kina \\
\cline { 2 - 7 } & LU 1 & LU 2 & LU 3 & LU 1 & LU 2 & LU 3 & LU 3 \\
\hline Temperatur Rerata (0C) & $\mathrm{S} 2$ & $\mathrm{~S} 2$ & $\mathrm{~S} 1$ & $\mathrm{~S} 1$ & $\mathrm{~S} 1$ & $\mathrm{~S} 2$ & $\mathrm{~S} 1$ \\
Curah Hujan (mm/Tahun) & $\mathrm{N}$ & $\mathrm{N}$ & $\mathrm{N}$ & $\mathrm{S} 1$ & $\mathrm{~S} 1$ & $\mathrm{~S} 1$ & $\mathrm{~S} 3$ \\
Drainase & $\mathrm{S} 1$ & $\mathrm{~S} 1$ & $\mathrm{~S} 1$ & $\mathrm{~S} 1$ & $\mathrm{~S} 1$ & $\mathrm{~S} 1$ & $\mathrm{~S} 1$ \\
Tekstur & $\mathrm{S} 1$ & $\mathrm{~S} 1$ & $\mathrm{~S} 1$ & $\mathrm{~S} 1$ & $\mathrm{~S} 1$ & $\mathrm{~S} 1$ & $\mathrm{~S} 1$ \\
Bahan Kasar (\%) & $\mathrm{S} 1$ & $\mathrm{~S} 1$ & $\mathrm{~S} 1$ & $\mathrm{~S} 1$ & $\mathrm{~S} 1$ & $\mathrm{~S} 1$ & $\mathrm{~S} 1$ \\
Kedalaman Tanah (cm) & $\mathrm{S} 3$ & $\mathrm{~S} 3$ & $\mathrm{~S} 3$ & $\mathrm{~S} 3$ & $\mathrm{~S} 3$ & $\mathrm{~S} 3$ & $\mathrm{~S} 3$ \\
pH H2O & $\mathrm{S} 2$ & $\mathrm{~S} 2$ & $\mathrm{~S} 2$ & $\mathrm{~S} 2$ & $\mathrm{~S} 2$ & $\mathrm{~S} 2$ & $\mathrm{~S} 1$ \\
Lereng (\%) & $\mathrm{S} 3$ & $\mathrm{~N}$ & $\mathrm{~N}$ & $\mathrm{~S} 3$ & $\mathrm{~N}$ & $\mathrm{~N}$ & $\mathrm{~N}$ \\
Bahaya Erosi & $\mathrm{N}$ & $\mathrm{N}$ & $\mathrm{N}$ & $\mathrm{N}$ & $\mathrm{N}$ & $\mathrm{N}$ & $\mathrm{N}$ \\
\hline Total & $\mathrm{N}$ we & $\mathrm{N}$ wse & $\mathrm{N}$ wse & $\mathrm{N} e$ & $\mathrm{~N} \mathrm{se}$ & $\mathrm{N} \mathrm{se}$ & $\mathrm{N} \mathrm{se}$ \\
\hline Keterangan: $w=$ Rerata curah hujan, $s=$ Lereng, dan $e=$ Bahaya erosi & &
\end{tabular}

Berdasarkan hasil analisis kesesuaian lahan pada beberapa komoditas alternatif LUT (Tabel 6) terlihat bahwa semua komoditas pada setiap LU memiliki klas kesesuain lahan akhir N. Faktor yang menjadi pembatas dalam penerapan LUT alternatif yaitu curah hujan yang tinggi pada tanaman kopi, dan lereng serta bahaya erosi pada semua komoditas. Klas S3 juga menjadi pertimbangan pada penerapan LUT alternatif. Klas S3 terdapat pada faktor kedalaman tanah untuk semua jenis tanaman, curah hujan pada tanaman kina dan lereng pada LU 1 pada tanaman teh dan kopi arabika. Klas kesesuaian lahan N atau S3 dapat ditingkatkan menjadi S2 ataupun S1 apabila kondisi lahan diperbaiki sesuai dengan kebutuhan tanaman yang akan di budidayakan di lokasi tersebut.

Upaya perbaikan lahan (land improvements) masih tetap diperlukan dalam penerapan LUT tanaman tahunan, seperti pembuatan terasering dan atau pembenahan terasering yang telah ada dan tidak efektif. Satuan lahan yang sangat miring lebih baik dihutankan kembali. Perbaikan lahan harus diprakarsai dan diinisiasi oleh pemerintah daerah serta melibatkan petani yang mempunyai lahan. Petani dilibatkan secara langsung agar mendapat pelajaran, pengalaman akan pentingnya serta manfaat menjaga dan memelihara lingkungan, agar proses degradasi lahan dapat dihentikan atau paling tidak meperlambat proses degradasi

Pengendalian aliran permukaan merupakan kunci utama. Pada daerah yang tidak rawan longsor, memperbesar resapan air dan sebagai konsekuensinya adalah memperkecil aliran permukaan merupakan pilihan utama. Sebaliknya, jika daerah tersebut rawan longsor, aliran permukaan perlu dialirkan sedemikian rupa sehingga tidak menjenuhi tanah dan tidak memperbesar erosi. 
Bayu Setiawan et al., / Vegetalika. 2018. 7(2): 1-15

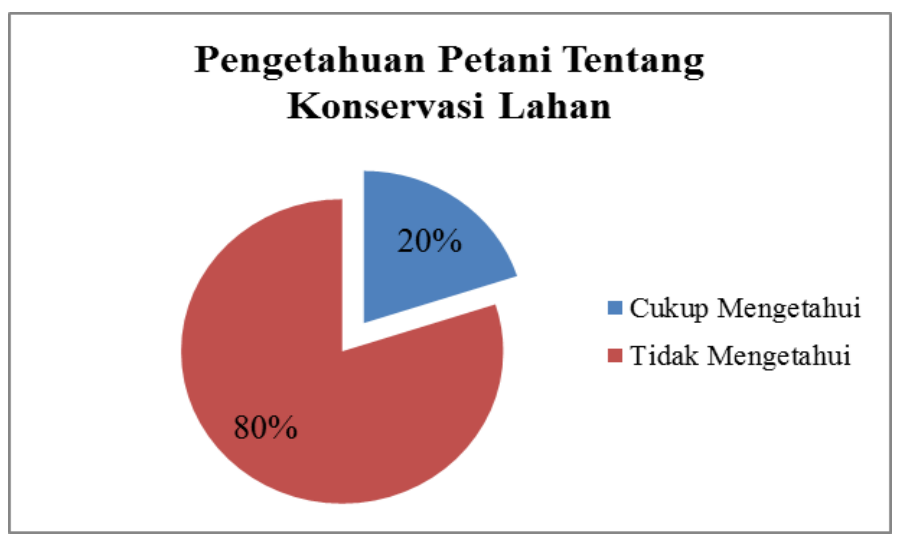

Gambar 4. Diagram pengetahuan petani tentang konservasi lahan

Berdasarkan hasil wawancara dengan petani di lokasi penelitian terkait pengetahuan tentang konservasi lahan hanya 6 orang $(20 \%)$ petani yang cukup mengetahui tentang konservasi lahan dan 24 orang (80\%) narasumber lainnya menyatakan tidak mengetahui tentang konservasi lahan. Hasil tersebut menunjukkan bahwa pengetahuan petani masih minim terkait dengan konservasi lahan. Hal ini merupakan kewajiban pemerintah selaku pembuat kebijakan untuk memberikan pengetahuan terhadap pemerintah.

Manajemen tanaman sebagai salah satu komponen pengelolaan teknologi pertanian diperlukan dalam sistem pertanian berkelanjutan karena sistem pertanaman intensif bisa mengarah pada pertukaran antara manfaat ekonomi dalam jangka pendek dan kerusakan lingkungan seperti degradasi kesuburan tanah dalam jangka panjang. Pemilhan tanaman serta cara bertanam harus memperhatikan memperhatikan faktorfaktor kondisi litologi, kelerengan, geologi, serta ekonomi. Pertanian pada lahan pegunungan memiliki pengaruh yang jelas bagi masyarakat banyak dibandingkan pertanian di lahan yang datar. Oleh karena itu diperlukan manajemen yang tepat agar pertanian dapat berkelanjutan dan bermanfaat.

Pemilihan tanaman tepat dapat menjadi solusi terhadap permasalahan konservasi lahan dan kebutuhan masyarakat petani. Tanaman yang ditanam harus memiliki nilai ekonomis yang tinggi serta aman terhadap kerusakan lahan. Selain itu kriteria kesesuaian lahan untuk komoditas yang akan ditanam harus sesuai dengan kondisi di lokasi penelitian. Menurut Erfandy (2010), tanaman keras yang ditanam pada lahan dan sebagai tanaman pagar pada pertanaman semusim selain bermanfaat sebagai penghambat aliran permukaan dan erosi, perakarannya sebagai pengikat struktur tanah yang dapat memperbesar ketahanan geser tanah. Alternatif penanganan yang efektif dengan berbasis vegetasi tanaman adalah sistem pertanaman lorong, 
Bayu Setiawan et al., / Vegetalika. 2018. 7(2): 1-15

penanaman rumput pada teras dan penanaman tanaman dengan kombinasi perakaran dalam dan dangkal. Penanaman tanaman dengan kombinasi perakaran sangat diperlukan.

Tabel 7. Pedoman pemilihan teknologi konservasi tanah secara mekanis dan vegetatif berdasarkan tingkat kemiringan lahan, erodibilitas tanah dan kedalaman solum

\begin{tabular}{|c|c|c|c|c|c|c|c|c|}
\hline \multirow{3}{*}{$\begin{array}{l}\text { Lereng } \\
(\%)\end{array}$} & \multicolumn{6}{|c|}{ Kedalaman solum $(\mathrm{cm}) /$ erodibilitas } & \multirow{2}{*}{\multicolumn{2}{|c|}{$\begin{array}{c}\text { Rekomendasi proporsi } \\
\operatorname{tanaman}(\%)\end{array}$}} \\
\hline & \multicolumn{2}{|c|}{$>90 \mathrm{~cm}$} & \multicolumn{2}{|c|}{$40-90 \mathrm{~cm}$} & \multicolumn{2}{|c|}{$<40 \mathrm{~cm}$} & & \\
\hline & Rendah & Tinggi & Rendah & Tinggi & Rendah & Tinggi & Semusim & Tahunan \\
\hline 1 & 2 & 3 & 4 & 5 & 6 & 7 & 8 & 9 \\
\hline $15-25$ & $\begin{array}{l}\text { TB, BL, PH, } \\
\text { SP, PT, RR, } \\
\text { ST }\end{array}$ & $\begin{array}{l}\text { TB, BL, PH } \\
\text {, SP, PT, R } \\
\text { R, ST }\end{array}$ & $\begin{array}{l}\text { TB, BL, PH, } \\
\text { SP, PT, RR, } \\
\text { ST }\end{array}$ & $\begin{array}{l}\text { TB, BL, PH, } \\
\text { SP, PT, RR, } \\
\text { ST }\end{array}$ & $\begin{array}{l}\text { TB, BL, PH, } \\
\text { SP, PT, RR, } \\
\text { ST }\end{array}$ & $\begin{array}{l}\text { TB, BL, PH, } \\
\text { SP, PT, RR, } \\
\text { ST }\end{array}$ & Maks 50 & Min 50 \\
\hline $25-40$ & $\begin{array}{l}\text { TB, BL, PH, } \\
\text { PT, }\end{array}$ & $\begin{array}{l}\text { TG, BL, PH } \\
\text {, PT }\end{array}$ & $\begin{array}{l}\text { TG, BL, PH } \\
\text {, PT }\end{array}$ & $\begin{array}{l}\text { TG, BL, PH } \\
\text {,PT }\end{array}$ & $\begin{array}{l}\text { TG, BL, PH, } \\
\text { PT }\end{array}$ & $\begin{array}{l}\text { TI, RR, BL, } \\
\text { PH, PT }\end{array}$ & Maks 25 & Min 75 \\
\hline$>40$ & TI, TK & TI, TK & TI, TK & TI, TK & TI, TK & TI, TK & 0 & 100 \\
\hline
\end{tabular}

Sumber: Peraturan Menteri Pertanian No 47 tahun 2006

Keterangan $: \mathrm{TB}=$ Teras bangku; $\mathrm{BL}=$ Budidaya lorong, $\mathrm{TG}=$ Teras gulud; $\mathrm{TI}=$ Teras Individu; $\mathrm{RR}=$ Rorak; $\mathrm{TK}=$ Teras kebun, $\mathrm{PH}=$ Pagar hidup; $\mathrm{ST}=$ Strip rumput atau strip tanaman alami; SP = Silvipastura; PT = Tanaman penutup tanah

Setelah adanya land improvement beberapa komoditas tanaman alternatif klas kesesuaian lahannya dapat menjadi sangat sesuai dan sesuai. Tanaman kopi arabika, teh dan kina dapat dikembangkan sebagai tanaman alternatif dalam kegiatan konservasi lahan. Kopi dipilih karena merupakan tanaman tahunan yang tidak terlalu memerlukan olah tanah yang terlalu intensif seperti yang dilakukan pada tanaman semusim sehingga kemantapan agregat tanah serta kesuburannya dapat diperbaiki secara bertahap. Tanaman teh dipilih karena merupakan tanaman perkebunan yang memiliki perakaran sangat baik dan dapat menjadi tanaman tepi sebagai pemantapan agregat tanah pada tepi teras. Tanaman kina dipilih sebagai alternatif LUT pada lahan dengan kelerengan yang sangat curam. Kina menjadi alternatif tanaman tahunan yang dapat dijadikan sebagai komponen utama tanaman hutan dalam pencegahan erosi yang sangat berat. 
Bayu Setiawan et al., / Vegetalika. 2018. 7(2): 1-15

Tabel 8. Kesesuaian lahan tanaman alternatif setelah perbaikan lahan

\begin{tabular}{lccccccc}
\hline \multirow{2}{*}{ Karakteristik lahan } & \multicolumn{3}{c}{ Kopi Arabika } & \multicolumn{3}{c}{ Teh } & Kina \\
\cline { 2 - 7 } & LU 1 & LU 2 & LU 3 & LU 1 & LU 2 & LU 3 & LU 3 \\
\hline Temperatur Rerata (0C) & S2 & S2 & S1 & S1 & S1 & S2 & S1 \\
Curah Hujan (mm/Tahun) & S2 & S2 & S2 & S1 & S1 & S1 & S2 \\
Drainase & S1 & S1 & S1 & S1 & S1 & S1 & S1 \\
Tekstur & S1 & S1 & S1 & S1 & S1 & S1 & S1 \\
Bahan Kasar (\%) & S1 & S1 & S1 & S1 & S1 & S1 & S1 \\
Kedalaman Tanah (cm) & S2 & S2 & S2 & S2 & S2 & S2 & S2 \\
pH H2O & S2 & S2 & S2 & S2 & S2 & S2 & S1 \\
Lereng (\%) & S2 & S2 & S2 & S2 & S2 & S2 & S2 \\
Bahaya Erosi & S2 & S2 & S2 & S2 & S2 & S2 & S2 \\
\hline
\end{tabular}

Perbaikan lahan merupakan konsekuensi/syarat suatu lahan yang sesuai moderat S2 atau marginal. Tanaman teh atau kopi di tanam di satuan lahan dengan kemiringan $15-25 \%$ perbaikan lahan relatif ringan. Teh/kopi ditanam secara single LUT/multiple LUT dengan mengikuti kontur kepadatan populasi 10.000 teh dan 1.500 kopi. Di antara barisan tanaman dibuat rorak (got buntu) dengan jarak lima meter posisi zig-zag, guna menangkap air limpasan dan unuk penempatan seresah sebagai bahan untuk memperbaiki kesuburan tanah (Huizing, 1980; Anonim 1981).

\section{KESIMPULAN}

1. Pemanfaatan lahan pertanian di lokasi penelitian berupa budidaya tanaman semusim dengan komoditas utama kentang (Solanum tuberosum L.) dengan teknik penanaman searah lereng serta minim tindakan konservasi lahan.

2. Tingkat bahaya erosi tergolong dalam klas sangat berat di semua satuan lahan yang menyebabkan potensi kerusakan lahan tinggi dalam kurun waktu yang singkat.

3. Cara mitigasi kerusakan lahan yang cocok untuk dilaksanakan yaitu dengan penanaman kopi arabika dan teh pada kelerengan curam (26\%-40\%) dan tanaman kina pada kelerengan sangat curam (>40\%). Perbaikan lahan yang dilakukan dengan pembuatan dan perbaikan teras, penanaman strip rumput, serta pembuatan rorak.

\section{UCAPAN TERIMA KASIH}

Ucapan terimakasih kami sampaikan pula pada perangkat dan seluruh masyarakat desa Giritirta, Orang Tua, Bapak Taufan Alam, Bapak Supriyanta dan 
Bayu Setiawan et al., / Vegetalika. 2018. 7(2): 1-15

Nurul Fatimah yang telah membantu dalam melaksanakan kegiatan penelitian dari awal hingga selesai.

\section{DAFTAR PUSTAKA}

Anonim. 2006. Tanaman Kopi Bisa Menahan Lahan dan Air Seperti Hutan. Sinar Tani Edisi 5-11 April 2006. http://pustaka.litbang.pertanian.go.id/inovasi/kl060411.pdf Diakses tanggal 16 Oktober 2017.

Anonim, 1981. Agricultural Compendium for Rural Development in The Tropics and Subtropics. Elsevier, Amsterdam.Arsyad, Sitanala. 1989. Konservasi Tanah dan Air. ITB, Bandung.

Bukhari. 2009. Desain agroforestry pada lahan kritis (studi kasus di Kecamatan Indrapuri, Kabupaten Aceh Besar). Tesis. Institut Pertanian Bogor, Bogor.

Departemen Kehutanan. 1998. Pedoman Penyusunan Rencana Teknik Lapangan Rehabilitasi Lahan dan Konservasi Tanah Daerah Aliran Sungai. Jakarta.

Erfandi, D. 2010. Sistem vegetasi dalam penanganan lahan rawan longsor pada areal pertanian. Prosiding Seminar Nasional Pertanian Ramah Lingkungan : 319-328.

Hidayat, M. Y. 2006. Evaluasi kesesuaian lahan untuk tanaman sengon (Paraserianthes falcataria (L) Nielsen) pada beberapa satuan kelas lereng. Skripsi. Institut Pertanian Bogor, Bogor.

Sumarhani. 2009. Agroforestry sebagai pemanfaatan lahan berkelanjutan di masa depan. Prosiding Seminar Nasional Agroforestry Universitas Lampung, Bandar Lampung.

Sumartono, D. 2011. Evaluasi lahan untuk kawasan lindung dan budidaya dengan aplikasi sistem informasi geografis (SIG) di Kabupaten Karanganyar, Jawa Tengah, Thesis. Universitas Muhammadiyah Surakarta, Solo.

Waluyo. S. 2015. Optimasi tipe penggunaan lahan pertanian berbasis agroekosistem di daerah aliran sungai putih Kabupaten Banjarnegara, Jawa Tengah. Disertasi. Universitas Gadjah Mada, Yogyakarta.

Wischmeier, W.H and Smith, D.D. 1978. Predicting Rainfall Erosion Losses, A Guide to Conservation Planning. Agriculture Handbook Number 537. United State Department of Agriculture : Preparad by Science and Education Administration. 